\title{
Impact of Roadside Landscape to Driving Behaviour; Lessons from Southern Highway, Sri Lanka.
}

\author{
Shameen Dharmasena ${ }^{1, a}$, Suresh Edirisooriya $2, b$ \\ $1 \& 2$ Department of Architecture, University of Moratuwa, Sri Lanka \\ ashameen1990@gmail.com, beatsuresh@uom.lk
}

\begin{abstract}
Lack of safety on roads has become a major issue in the world due to over population as well as increasing number of vehicles. This has led to many fatal incidents. Many factors affect accidents on roads and among them, 'driving behavior' plays a crucial role.

Road landscapes create the character and the spatial quality of the spaces the drivers move through. The rate of information gathered from the surrounding is vital for safety of driving while the accuracy of this information depends on the visual perception of the drivers.

'Southern Expressway', introduced recently, allowed people to move quickly from Colombo to Southern destinations of Sri Lanka. Many accidents have taken place in this highway. It can be hypothesized that the spatial qualities of the road landscape might have contributed to the accidents.

The study focused on identifying the spatial characteristics of Southern Highway. Data was collected by two means; the recorded accident data from Southern highway and a live recording of the driving experience. Analysis was based on accidents recorded and "black-spots" identified. Live recordings of the expressway was analyzed to understand the spatial characteristics in the identified 'black-spots'.

In conclusion, the study reveals that there is a direct influence from the spatial characteristics of black-spots on road accidents.
\end{abstract}

Keywords: Road safety, Road landscape, Driving behavior, spatial characteristics.

\section{Introduction}

As a developing country, Sri Lanka recently decided to develop the transportation network to world standards. One of these attempts has been the expressway system. One of the major issues arising is related to road safety.

When analyzing the road accidents reported each year, it is noted that a large number of them have been influenced by the road environment and its landscape. Therefore, this study focuses on the impact of physical environment of the roads on driving behaviours.

To ensure road safety, road accidents should be controlled. Driving is a motion related action, which experiences landscapes through different spaces. Driving behaviour is influenced by the surrounding physical space of the driver. A driver experiences the space of the road landscape relative to the speed. When a driver is unable to capture the 
real time spatial changes in correct time, accidents may happen. Different reasons lead to road accidents, such as,

- The environment

- Road users

- Vehicle defects

- Driving behaviours.

\section{Driving Behavior}

Driving is a complex activity, which has to engage all the senses of people. It is an intellectual, cognitive and emotional experience. A driver should always maintain his mental and physical states at a satisfactory level while driving. When considering road safety, driving behaviour holds an important role.

It is found that $92 \%$ of road accidents are caused by human factors. (Importance of a strategic plan to prevent road accidents in Sri Lanka, 2012)

\section{Driving behaviour and Visual Perception}

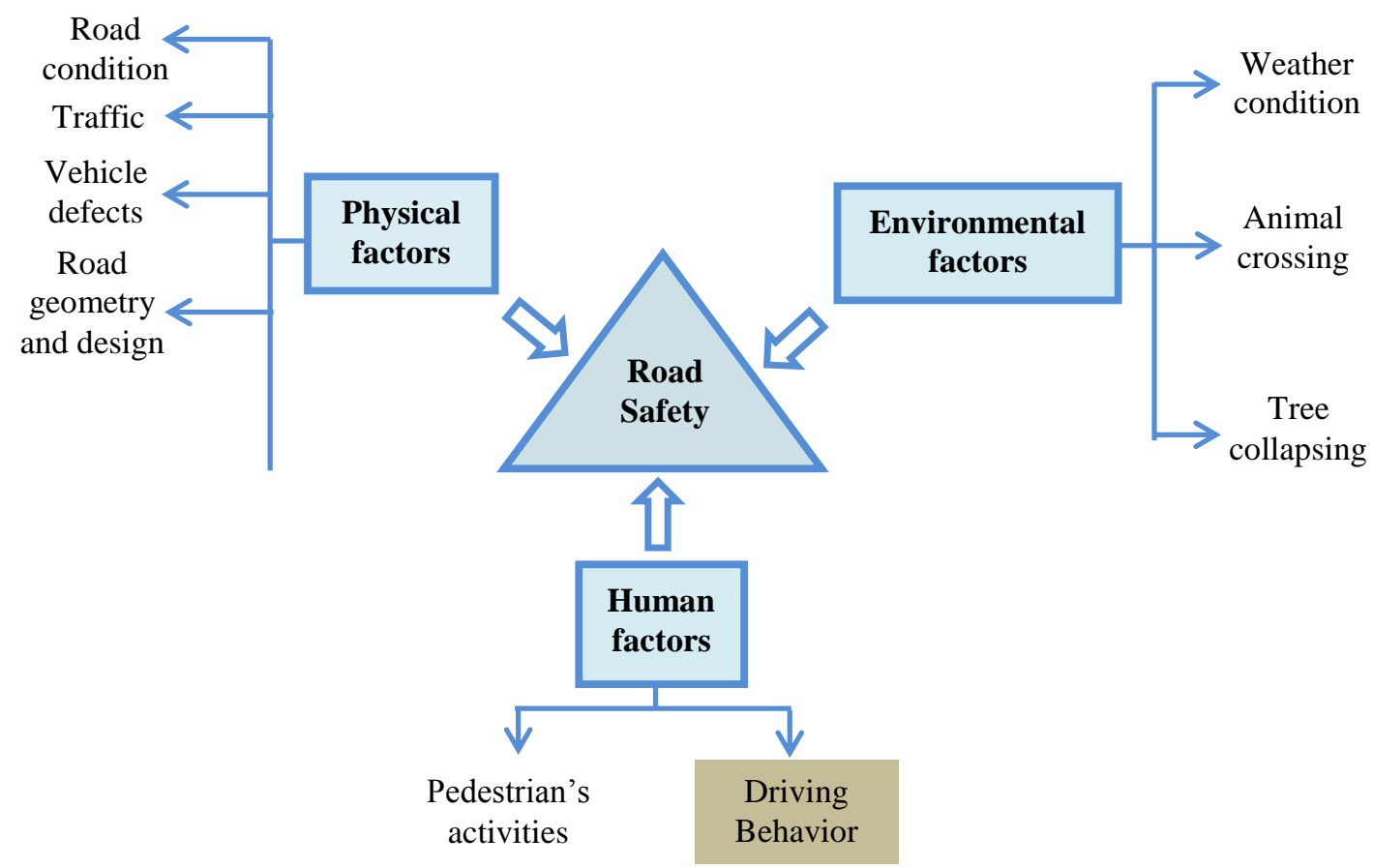

Fig. 1: Factors that determine Road Safety

Source : Author

Kaplan and Kaplan (as cited by in Antonson , et al, 2009;494) explain that people experience and react to a landscape based on cognition and their experiences. It is also found that most anthropogenic activities are the results of what the human eye perceives from the surrounding landscape. 
Many Researchers have found that fatigue, drowsiness, vigilance, alertness, activation and arousal are the frequently occurring negative processes with the visually perceived information from the environment when performing driving. (Thiffault \& Bergeron, 2002; Antonson et al., 2009; Lal \& Craig, 2001) Therefore, the effective action of driving depends on the individual's visual perception. The exogenous factors and psychological factors determine the visual perception of drivers.

\section{Driving Behaviour and Road Landscape}

Matijosaitiene says that "the road landscape is considered as a product created by a human and nature which should provide pleasure to its main users" (2011)

The term 'road landscape' is defined as the visible road environment which includes all physical surroundings and components such as, roads, road equipment and signs, Electricity transmission lines, vegetation, service infrastructure and other buildings which are located not further than $3 \mathrm{~km}$ from the axis of a road.

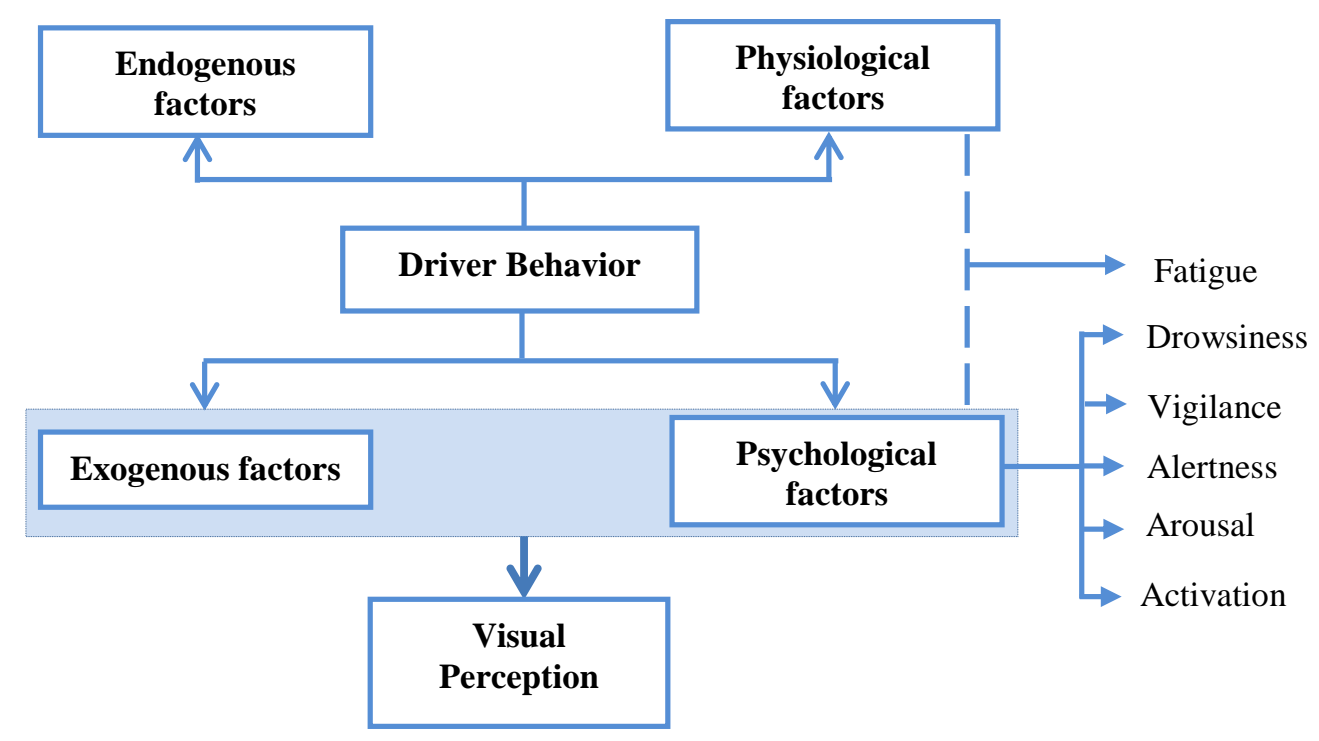

Fig. 2: Driving Behaviour and Visual Perception Source: Author 


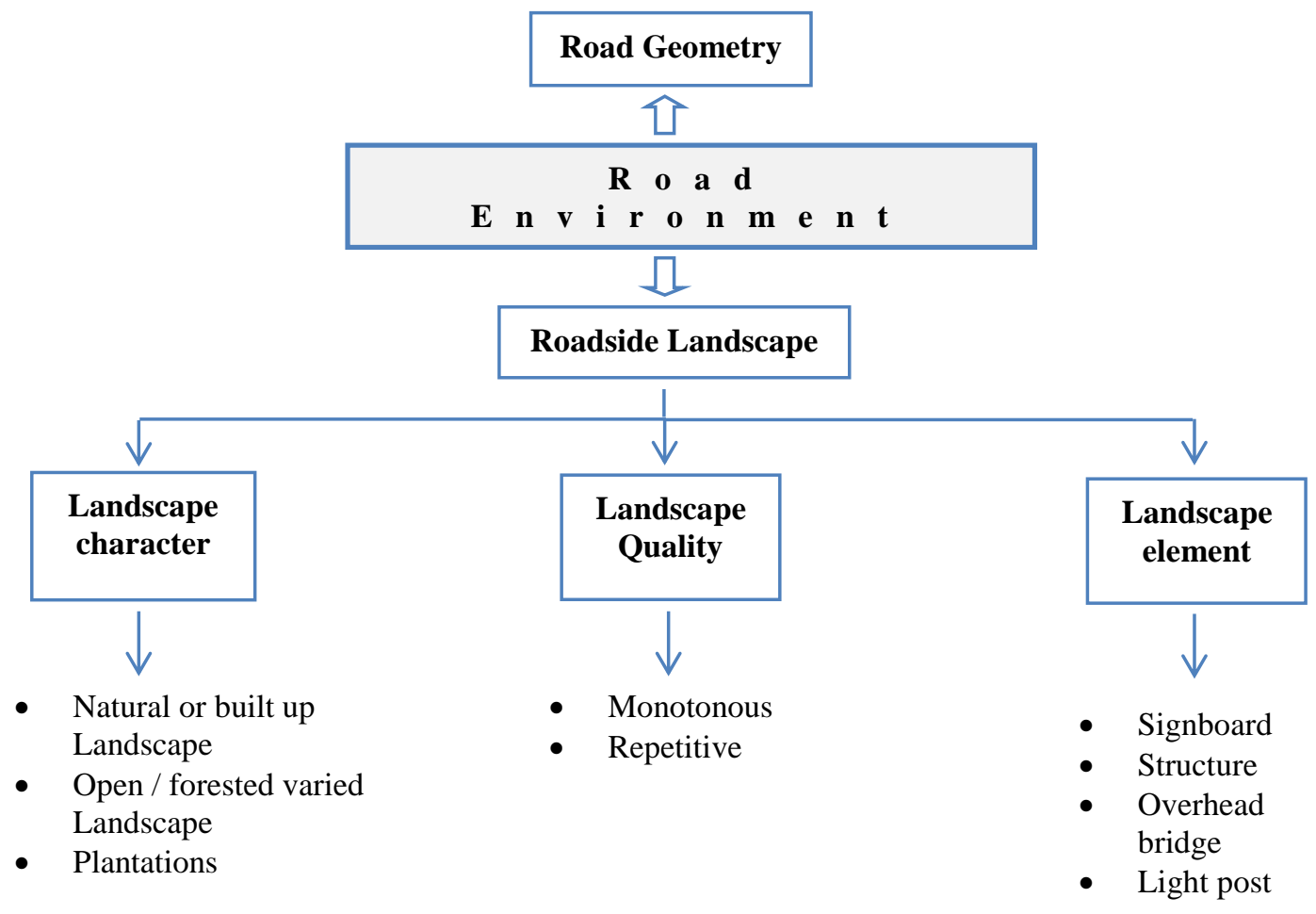

Fig. 3: Categories of Road Environment Source : Author

The 'driver behavior' is an interactive activity by a person which is a collection of different skills and processes.

The driving skills can be divided into four broad categories,

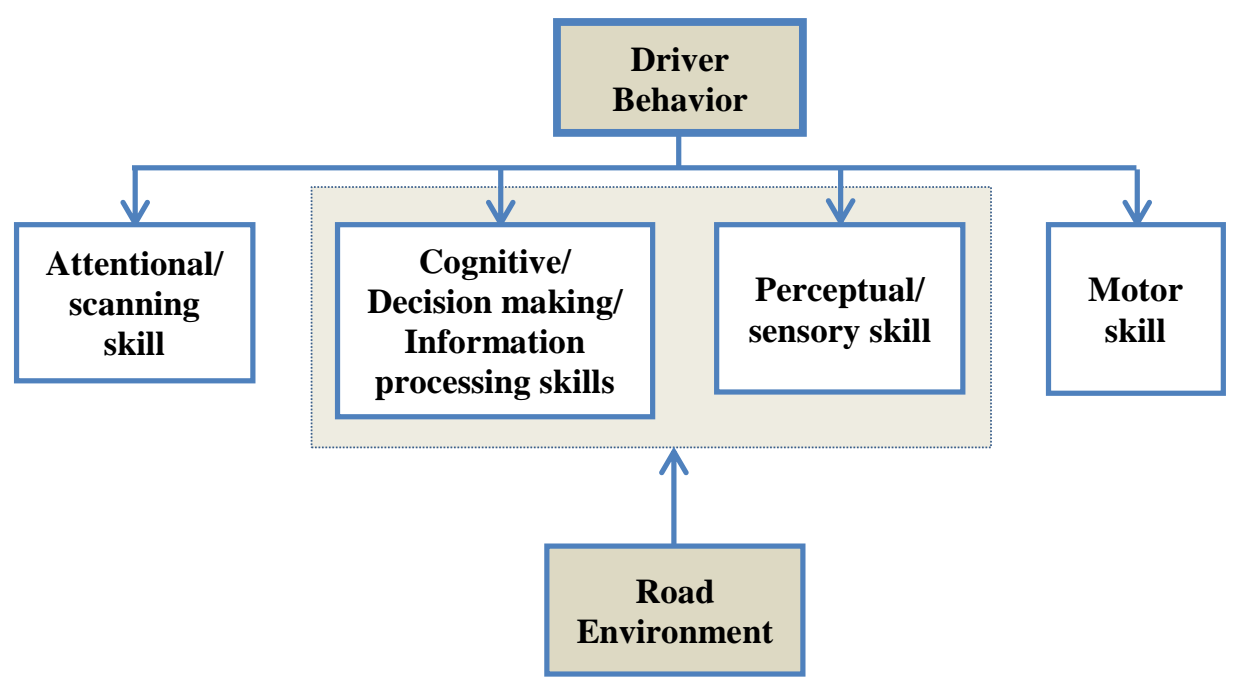

Fig. 4: Skills of driving behaviour

Source: Author 
According to Küllers' model of the basic emotional process, "driving behavior is related to the physical environment, other road users, the driving task, the individual factors and own abilities, and to the interaction among them" (Matijošaitienè \& Navickaite, 2012). Road environment has a significant impact on the driver's perceptual/sensory skills and cognitive/decision making and information processing skills.

However, driving is a visual experience of outside driving environments. The drivers limit their visual experience mainly to the larger spaces and land forms, because the drivers always focus on the narrow band created by the road. But, drivers may be interested to expose to a broader visual field even for a brief moment. But the increasing speed reduces the visual field.

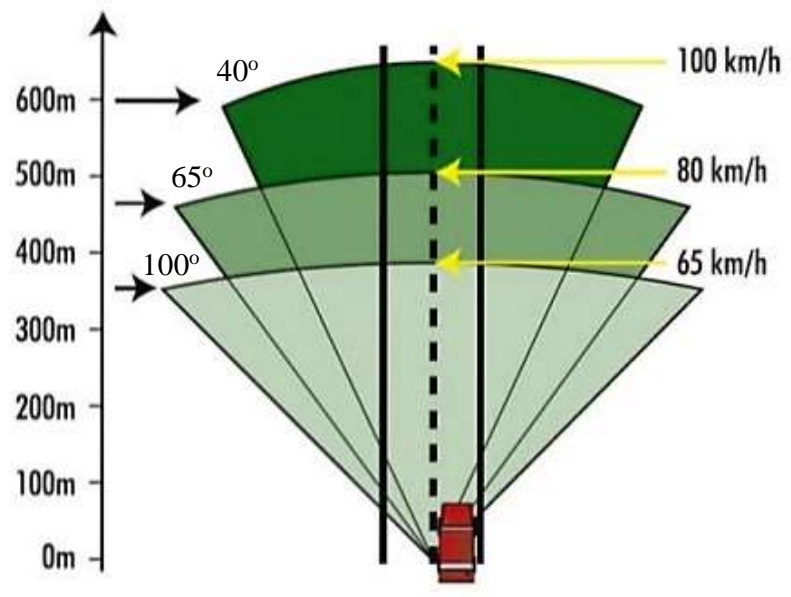

Fig. 5: Speed and field of vision

Source: The Role of Road Engineering in Combatting Driver

Distraction and Fatigue Road Safety Risks, (2015)

The Fig. 4 above shows when the speed is increased, the field of vision of the driver narrows and the driver focuses onto more distant views. Drivers pay a greater attention to what is beside the road. Thus the roads and highways should have visually pleasing environments. The landscapes of roadside environments should be considered when designing roads and highways. Matijošaitienè and Navickaite (2012) found that in Germany, $68 \%$ of all the car accidents happened due to the wrong design of road and its landscape, and because of insufficient information of road and its landscape. Therefore, the road designers, landscape architects and traffic engineers have the potential to increase the level of visual stimulation of the roads and highways by changing the surrounding landscape, including curves to the road design and road information boards like kilometer counters. These encourage mental calculations that can enhance alertness. Many studies prove that drowsy driving can be reduced by design efforts in highway designing. Thiffault \& Bergeron (2002) point out that visual stimulation can be used as countermeasures to eliminate driver fatigue.

Thus, the roadside landscapes have a huge impact on the road safety in terms of driver behaviour. 


\section{LITERATURE REVIEW}

\section{Spatial Characteristics in Road Landscapes}

Road landscapes are diversifying according to its' spatial characteristics. Gong et al (2005) identified six models to integrate planning, design and construction of highway landscapes. They are, the models of highway alignment, the model of pavement and side slopes, the model of highway construction, the model of subsidiary facilities along the highway corridor, the model of highway greening and other landscape model. The following spatial characteristics in road landscapes have been identified from those six models.

- $\quad$ Solidity \& degree of enclosure

- $\quad$ Differentiate of forms

- Proportion or scale of the space

- Gradient of the slopes/embankments

These spatial characteristics in road landscapes have the potential to affect driving behaviour positively or negatively.

\section{Solidity \& Degree of Enclosure}

Solidity is a vital factor and can be experienced as solids or voids along the roadways which are sometimes created by rocky slopes or soil berms and paddy lands or bare lands.

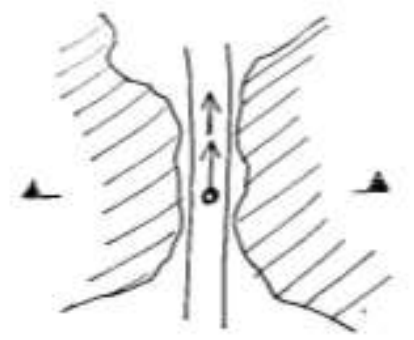

PLAN

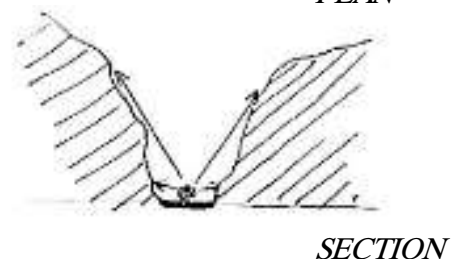

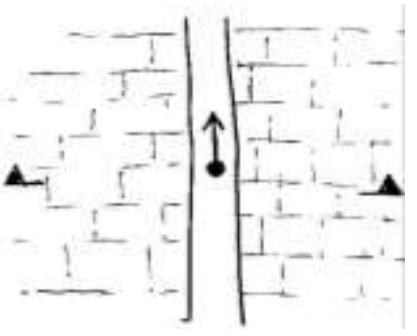

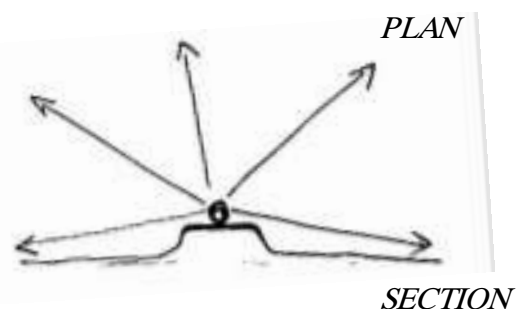

Fig. 6: Solidity \& degree of enclosure

Source: Author

When approaching from void to solid or solid to void affect psychologically differently to the observers. Brude \& Wretling (as cited in Antonson et al., 2009) write that the 'accident risk has been shown to be higher in open terrain with a monotonous road experience and regular geometry than in closed forested terrain'. 
When someone moves through a narrow solid space, it feels very uncomfortable and constricts the mind. Thus, it induces the mind to escape and move fast. The speed will increase in this kind of spaces. When moving through open lands, it relaxes the driver's mind by spreading the views of the landscape. Therefore, in these spaces the speed will automatically reduce.

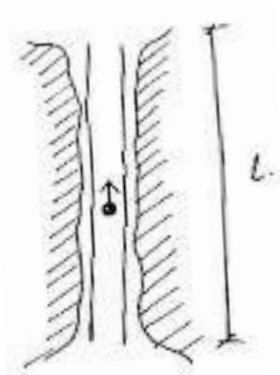

When moving through solid or void spaces, the distance matters a lot. If the solid /void distance increases, the road landscape turns into a monotonous space. It depends on the relative speed of the vehicle. Thus, when designing the roadways it is important to have a composition of solid \& void spaces.

Fig. 7: Distance of a solid/void matters a lot Source: Author

\section{Differentiate of forms}

People always identified 'forms' first when they expose to a scenery, then identify the details such as colors, lines etc. So, the forms in the road landscape support the legibility of the roadway. Lack of variations in the forms creates a monotonous roadscape, which draws the drivers to fatigue, drowsiness and hypo-vigilance.

The study of Vagverket (as cited in Antonson et al., 2009) mention that the spatial form of a road or street should give a clear visual guidance and signals to drivers, regarding the suitable speed and driving behaviour.

Drivers limit their visual experience mainly to larger landforms and spaces, since they limit their focus in to a narrow band according to the speed. (Appleyard, Lynch, \& Myer, 1965) So, often they concentrate more about the immediate verge of the road. The driving behaviour changes according to the landscape form of the immediate verge of the road.

\section{Proportion or scale of the space}

According to the research, 'A new concept of Landscape design in highway construction' (Gong, Xie, XU, FU, \& LI, 2005) it is highlighted that the cross section of the highway and the organization of its space is a crucial factor to consider in planning, designing and construction phase of the highway landscapes. Proportion or scale of the space creates a huge psychological impact to the driving in a highway. When a roadway falls through a landscape, it creates different spaces in different proportions.

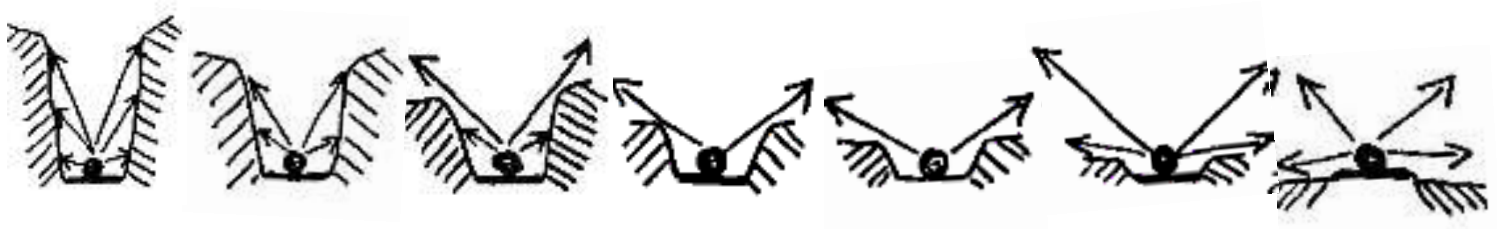

Fig. 8: Proportion or scale of the space

Source: Author 
According to the above diagramme, in a space, where the proportion is much larger than the observer it is more uncomfortable to drive through. It psychologically congested mind of the driver. When subsequently reduce the proportion it seems psychologically more comfortable to the driver, the mind expand and positively affected.

\section{Gradient of the slopes/ Embankments}

Gradient of the slopes/embankments is also impact to the driving behaviour, as figure 11 indicates that, when larger the gradient its' difficult to drive through the space. So, there are standard gradients to final slopes when constructing the highways.
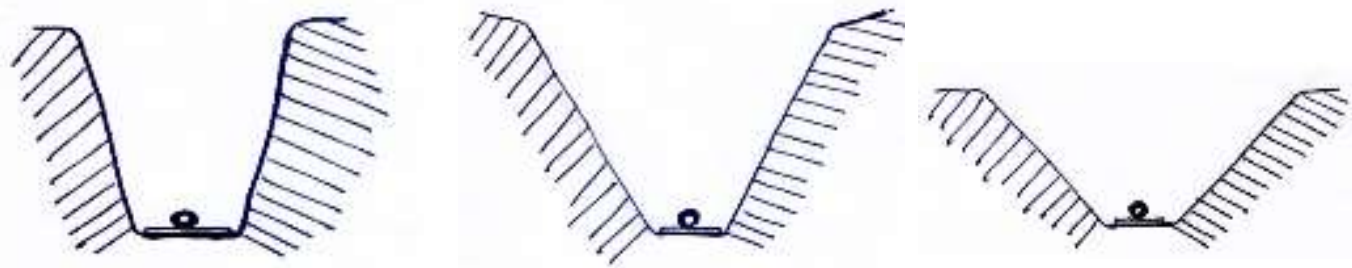

Fig. 9: Gradient of the slopes/embankments

Source: Author

Zhiyong's study (as cited in (Gong, Xie, XU, FU, \& LI, 2005) mentioned that the road users are less able to have head movement, as vehicle speeds up in a certain direction. Thus, their attention would be directed to the lane and side slopes. Road lane and side slope view can ensure the safety of road users and give them better views.

The side slope view, especially in cuttings and embankments is highly visible to the road users in highways, so that the form and the angles of the slopes decides the visual quality of the scenery of highways. Thus, the form of the side slopes should be changed as often as possible, the vegetation can be used in upper slopes to change the views with time, to absorb the noise and lessen driver fatigue.

\section{Experience of Road Landscape in Highways}

There are many characteristics in highway landscapes that affect the experience of driving in highways. The different stages of highway experience is processed with the spatial sequences made up of many elements in landscape.

The study done by (Appleyard et al., 1965) found that two-third of all elements experienced by the driver in highway are straight ahead and only one-third of elements are either in the right and left sides. Almost all things seen to the side of the road were obliquely forward to the driving direction rather than perpendicular of backward. 


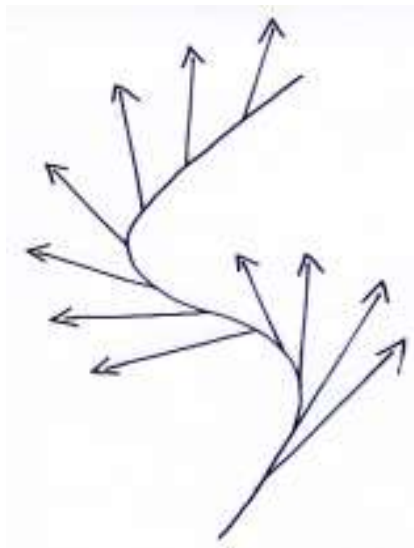

Fig. 10: Change of visual focus in highway driving Source: Author

The focus of attention is regularly switched from side to side. As mentioned above, when the speed increases, the driver's attention is confined to a narrow forward angle. The attention may shift to more distant and relatively stable elements. The landmarks are seen in clusters rather than single objects, larger landforms and spaces make commands to the driver and the scenes are changed from detail to generality. (Appleyard et al., 1965)

\section{Sense of Motion in Highways}

Drivers are aware about the speed at which they move by interpreting the apparent motion of surrounding objects, which they know are fixed. In a highway, drivers always move with visual clues and illusions, such as the outward radiation of details and textures from the point of dead (Fig. 10A), the apparent rotation of near objects around far objects (Fig. 10B), the growth of objects from the point of dead (Fig. 10C) etc.
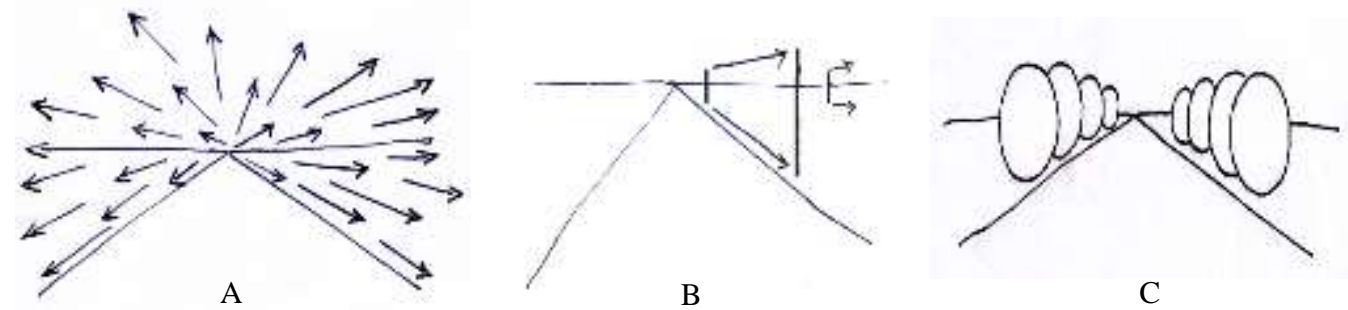

Fig. 11: Visual experience of highway driving Source: Author

Sense of motion in highways is mainly experienced as visual sequences. A proper continuity of the visual sequences is more important when driving safely. The road alignment, the road landscape, the form of the space and many other factors contribute to the continuity of visual sequences.

The visual field of the driver, not only be interpreted as a series of distant views, or a collection of objects in motion, but also as a space with solids and voids. Therefore, 
the sensation of driving through highways is different from spatial form. It can be confined spaces or flat terrains.
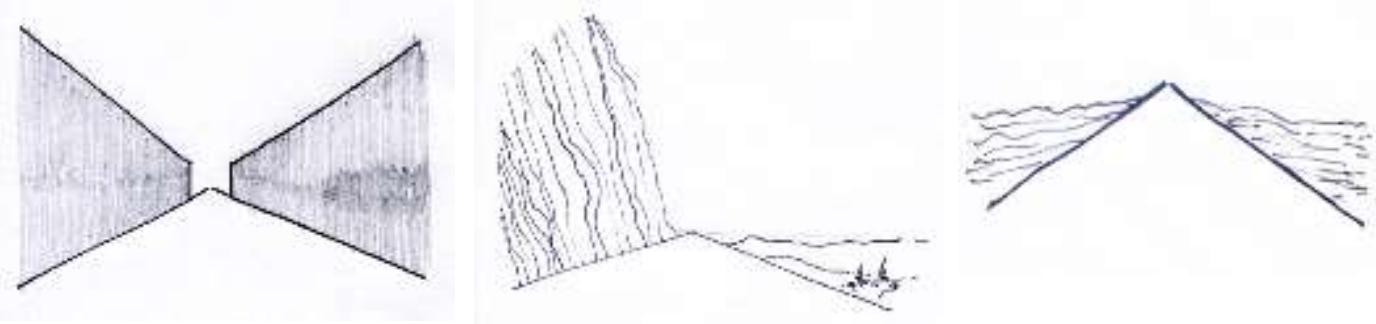

Fig. 12: Variation of spatial form in highway driving Source: Author

\section{Research Methodology}

Southern Expressway is selected a case study, considering its' highest Average Data Traffic (ADT) with comparing other two expressways in Sri Lanka.

The study progressed through three stages.

$$
\begin{aligned}
& \text { Stage } 01 \text { - Literature Review to form theoretical Framework } \\
& \begin{array}{|l|l|}
\hline \text { Stage } 02 & \text { - Phase } 01 \text { - Accident data collection } \\
\text { (Data Collection) } & \text { - Phase } 02 \text { - Field Data collection }
\end{array}
\end{aligned}
$$

The recorded accident data in Southern highway was categorized according to its cause, location, time, weather, type, vehicle etc. In Stage 02 phase 01, the recorded accident data has been categorized considering 'accident causes' and 'Locations'. Then identified the accident 'Black- Spots' (high risk accident locations) in terms of driving behaviours. The spatial characteristics of road landscapes mentioned below have been analyzed from the identified two black spots from both directions. The study is confined to analyze only major three spatial characteristics due to the time limitations and scope of work.

1. Solidity \& degree of enclosure

2. Differentiate of forms

3. Proportion-scale of the space with respect to the observer

The above-mentioned spatial characteristics analyzed within a $7 \mathrm{~km}$ stretch, $4 \mathrm{~km}$ before $\& 2 \mathrm{~km}$ after identified the 'Black-Spot'. 


\section{Data Collection and Analysis}

The Southern Expressway runs up to $126 \mathrm{~km}$ from Kottawa to Matara with 11 interchanges. From the date of opening in November 2011 up to February 2016, there have been 2602 accidents recorded in both directions, which was the highest among other expressways in Sri Lanka.

The recorded accident data were collected by the Expressway Operation Maintenance and Management Division (EOM \& M Division) and sorted according to the accident location. Through the sorted data, that the most accident prone areas in Southern highway on both directions have been identified. Causes of accidents were identified as main three factors (physical factors, environment factors and human factors) to identify the percentage of driving behaviour related accidents. Again the driving behaviour related accidents according to the 'location' were sorted, to identify the accident prone areas of driving behaviour related accidents. A 'dot density measure' was applied to the identified accident prone areas to recognize the specific locations ('Black-Spots') of driving behaviour related accidents. The identified Black-Spots were used to study the Spatial Characteristics of Road Landscape.

When analyzing the recorded accidents that happened in the Southern Highway, one can identify some specific areas in both directions, which have recorded the most number of accidents.

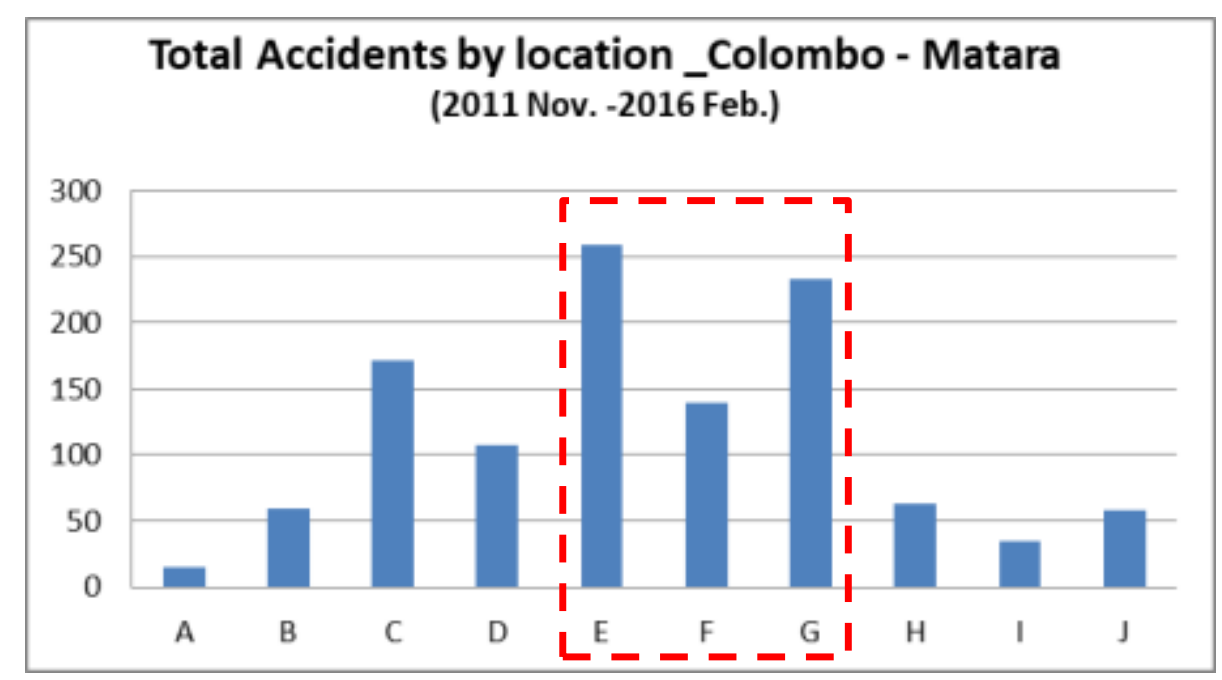

Fig. 13: Total Accidents by location_Colombo - Matara direction Source: Database-EOM \& M division, compiled by Author 


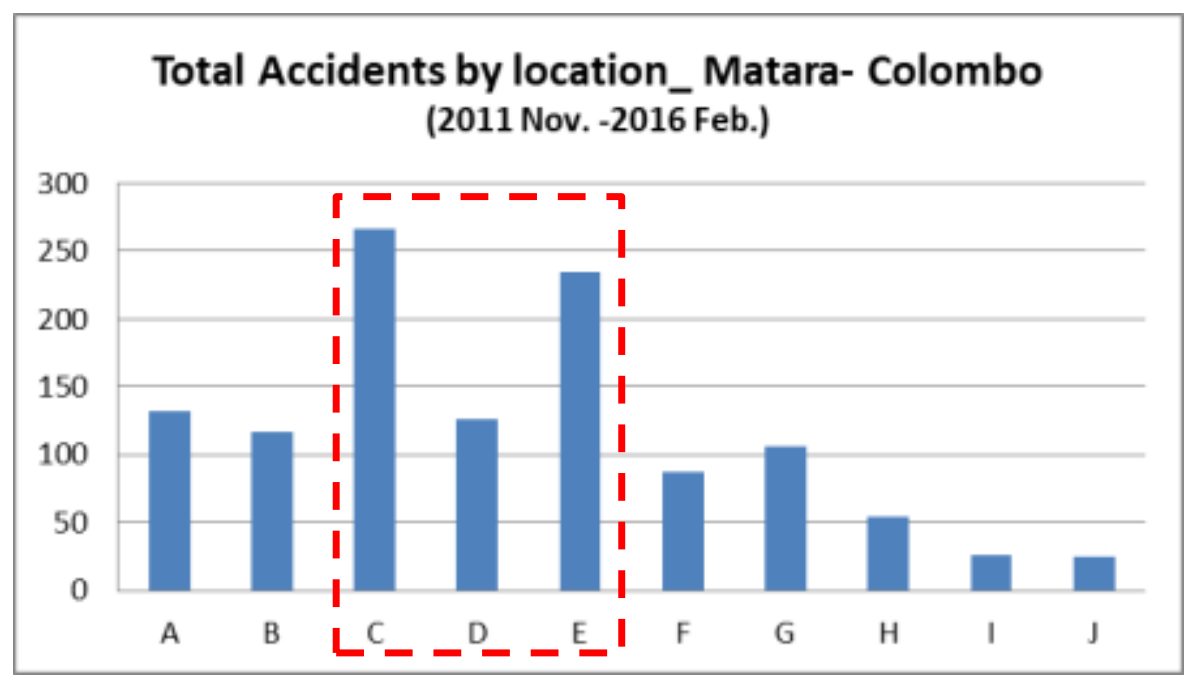

Fig. 14: Total Accidents by location_ Matara- Colombo direction Source: Database-EOM \& M division. comniled bv Author

Table 1- Highway Interchanges and distances

\begin{tabular}{|c|c|c|c|c|c|}
\hline & DISTANCE & INTERCHANGE & & DISTANCE & INTERCHANGE \\
\hline $\mathrm{A}$ & $0-6 \mathrm{~km}$ & $\begin{array}{c}\text { Kottawa- } \\
\text { Kahathuduwa }\end{array}$ & $\mathrm{F}$ & $68-80 \mathrm{~km}$ & $\begin{array}{c}\text { Kurundugaha- } \\
\text { Baddegama }\end{array}$ \\
\hline $\mathrm{B}$ & $6-14 \mathrm{~km}$ & $\begin{array}{c}\text { Kahathuduwa- } \\
\text { Gelanigama }\end{array}$ & $\mathrm{G}$ & $80-96 \mathrm{~km}$ & $\begin{array}{c}\text { Baddegama- } \\
\text { Pinnaduwa }\end{array}$ \\
\hline $\mathrm{C}$ & $14-35 \mathrm{~km}$ & $\begin{array}{c}\text { Gelanigama- } \\
\text { Dodangoda }\end{array}$ & $\mathrm{H}$ & $\begin{array}{c}96-108.4 \\
\mathrm{~km}\end{array}$ & $\begin{array}{c}\text { Pinnaduwa- } \\
\text { Imaduwa }\end{array}$ \\
\hline $\mathrm{D}$ & $35-46 \mathrm{~km}$ & $\begin{array}{c}\text { Dodangoda- } \\
\text { Welipenna }\end{array}$ & $\mathrm{I}$ & $\begin{array}{c}108.4- \\
116.3 \mathrm{~km}\end{array}$ & $\begin{array}{c}\text { Imaduwa- } \\
\text { Kokmaduwa }\end{array}$ \\
\hline $\mathrm{E}$ & $46-68 \mathrm{~km}$ & $\begin{array}{c}\text { Welipenna- } \\
\text { Kurungugaha }\end{array}$ & $\mathrm{J}$ & $\begin{array}{c}116.3-126 \\
\mathrm{~km}\end{array}$ & $\begin{array}{c}\text { Kokmaduwa- } \\
\text { Godagama }\end{array}$ \\
\hline
\end{tabular}

Source: Author

When carefully analyzing above charts, it is noted that most accidents have happened in same areas in both directions. This suggests that there may be a contribution from road landscape to those accidents.

The study is conducted during the daytime, because two third of all accidents in the Southern Highway happened during day time. (Database-EOM \& M division, Sothern Highway)

According to the accident data collected from the Southern highway EOM \& M division, the road accidents mainly happened according to three factors.

\section{Human Factors}

\section{Physical Factors}

\section{Environmental Factors}

The 'human factors' include all the errors from the drivers' side which had caused accidents. The 'physical factors' include all the issues from external environment and the vehicle. The 'environmental factors' include all the accidents that happened due to the 
issues from the environment. The accidents related to the driving behaviour were included in the human factor's column.

These are the causes of accidents which were recorded in the Southern Highway from 2011 November - 2016 February. The data were collected from the Expressway Operation Maintenance and Management Division.(EOM \& M Division)

Table 2 - Accidents by cause in southern highway

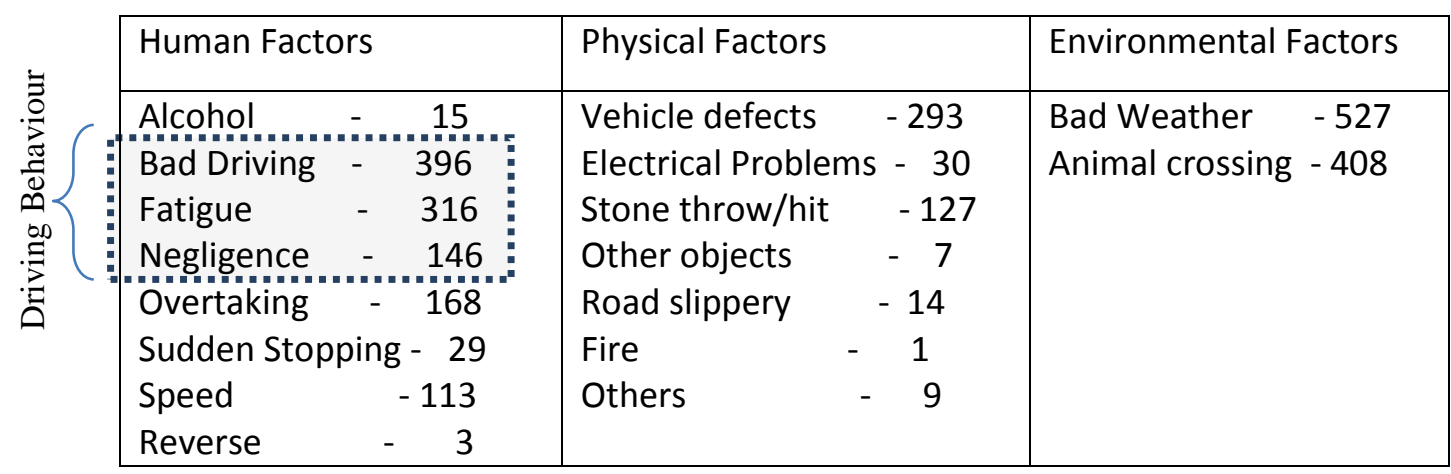

Source: Expressway Operation Maintenance and Management

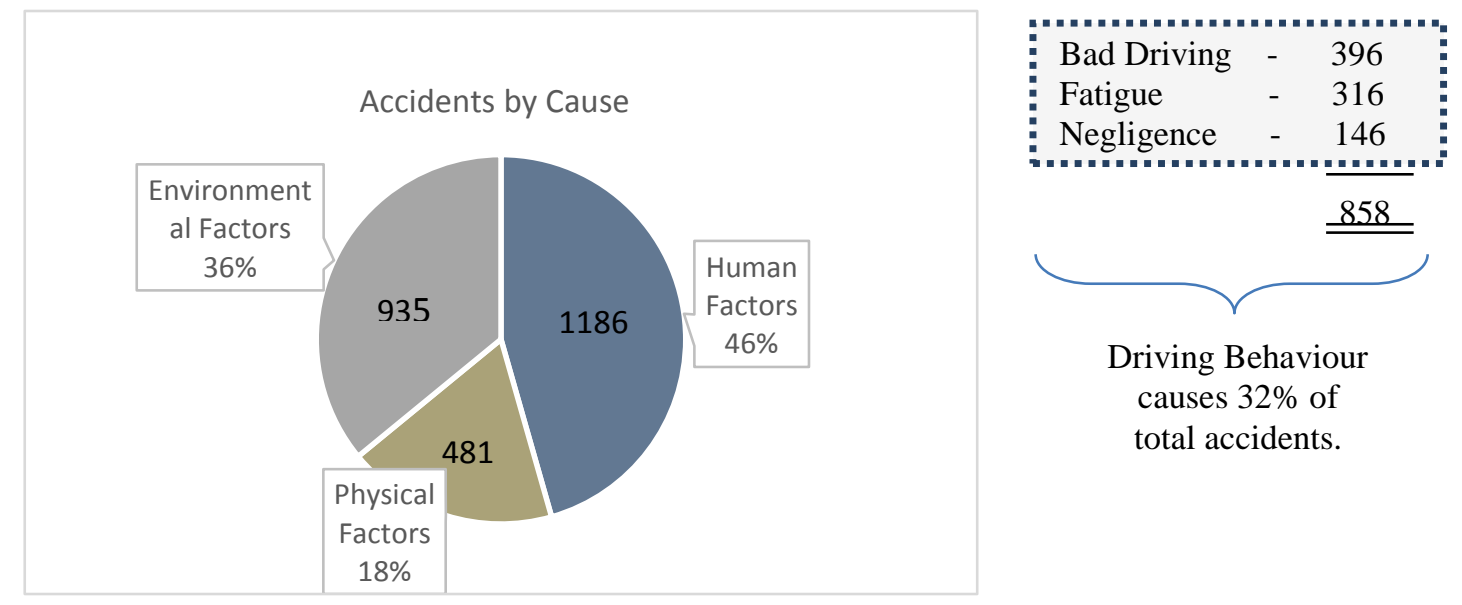

Fig. 15: Percentage of accidents by cause- Southern Highwav

According to the above analysis, human factors have contributed to $46 \%$ of the accidents in the Southern highway. Environmental factors have contributed to $36 \%$ of accidents and physical factors have contributed to $18 \%$ of accidents.

Driving behavior related accidents (accidents caused by bad driving, fatigue, and negligence) contributed to $32 \%$ of all accidents. To further analyze, the study focused on to the driving behaviour related accidents.

Most accidents recorded were between Kurundugahahetekma - Baddegama from Colombo to Matara direction. Then, a dot density measure has been used to identify the specific black-spot between $70 \mathrm{~km}-90 \mathrm{~km}$. From that, it can be concluded that the most number of accidents took place between $89 \mathrm{~km}$ and $90 \mathrm{~km}$. 
F - Kurundugahahetekma- Baddegama Interchange (68-80 km)

G- Baddegama- Pinnaduwa Interchange (80-96 km)

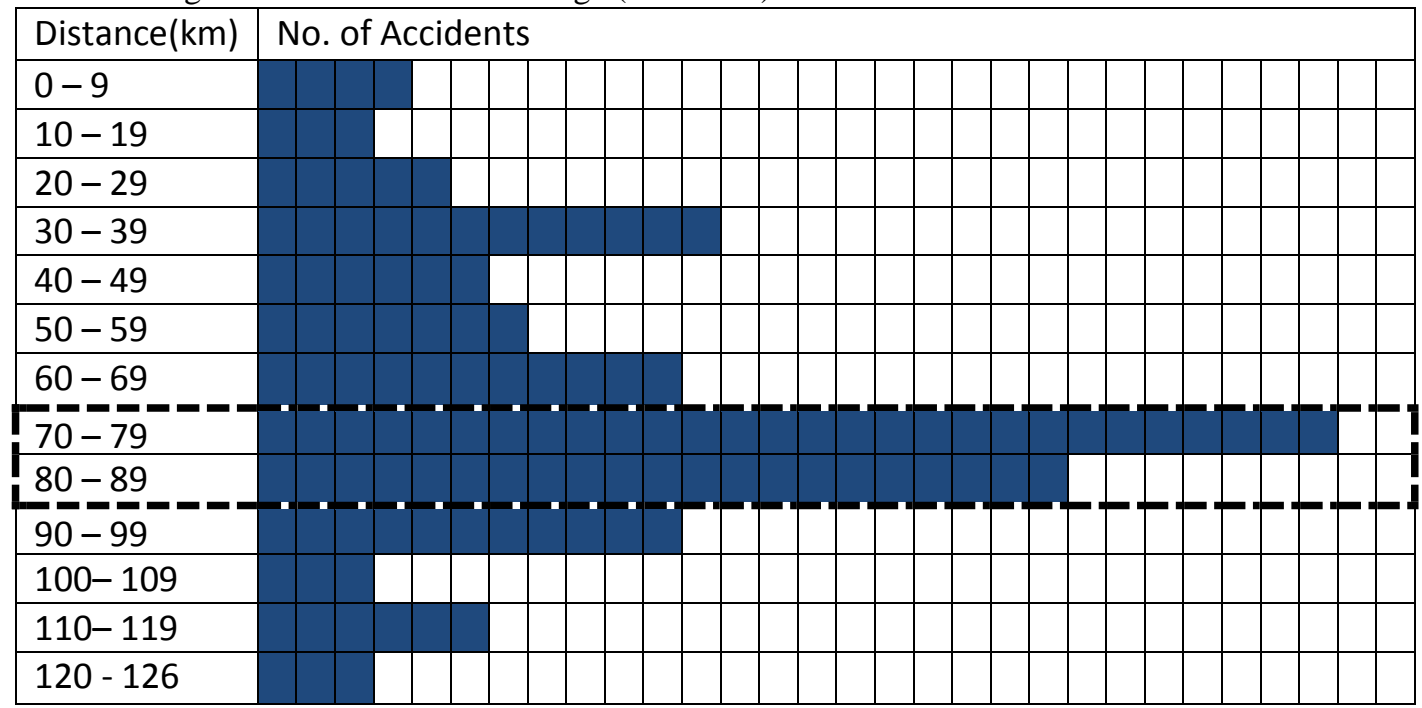

No. of Accidents

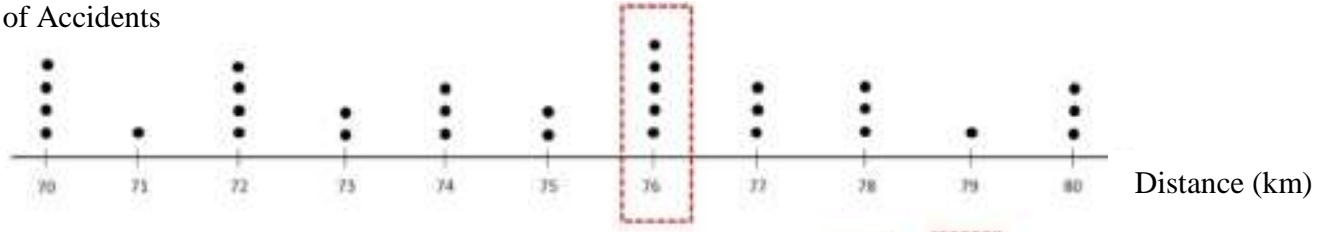

No. of Accidents

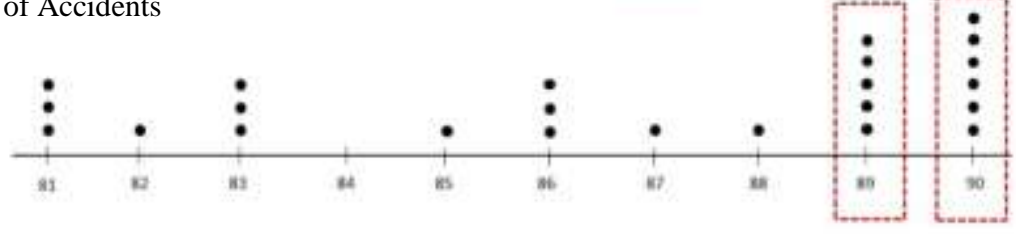

Distance $(\mathrm{km})$

Fig. 16: Dot-Density measure to identify black spots, Colombo to Matara direction Source: Author

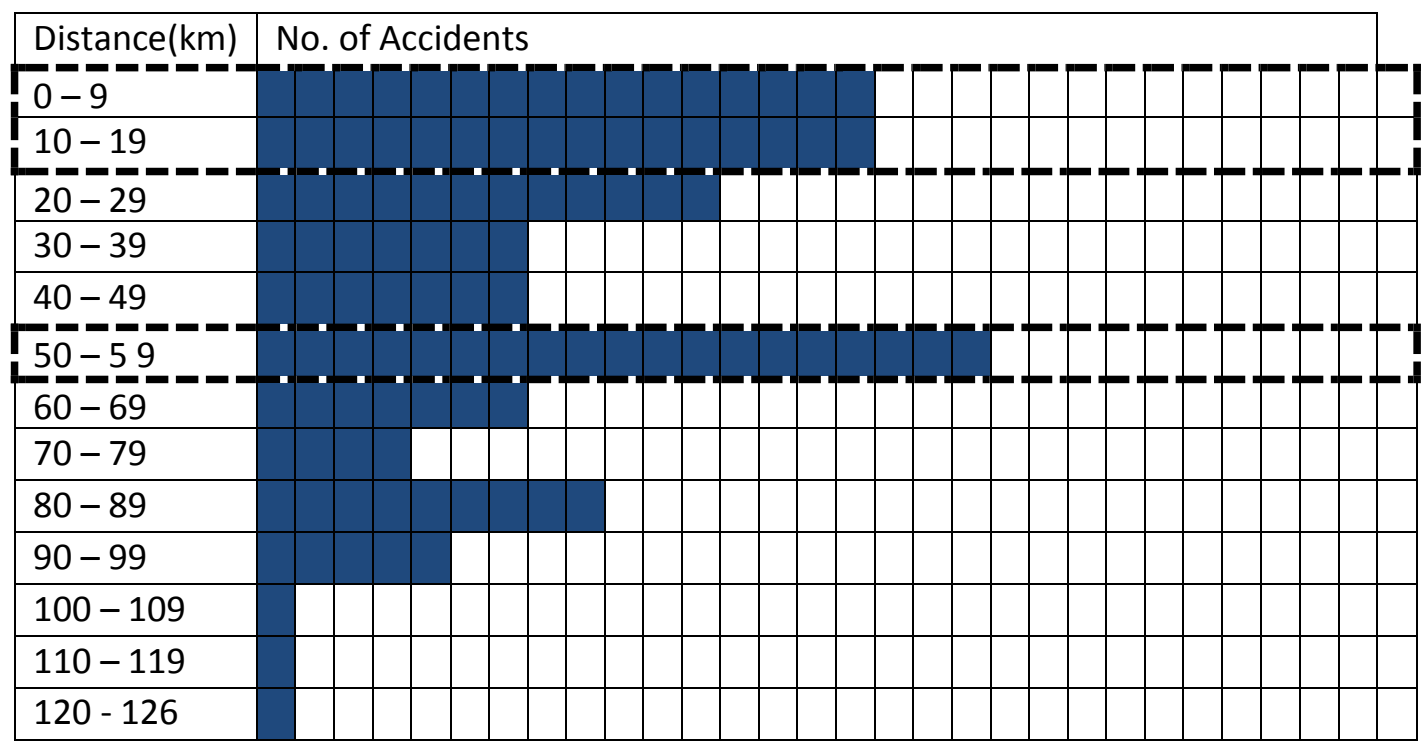


A - Kottawa - Kahathududwa Interchange (0-6 km)

B - Kahathuduwa- Gelanigama Interchange (6- $14 \mathrm{~km})$

C - Gelanigama- Dodangoda Interchange (14- 35km)

E - Welipenna - Kurundugahahetekma Interchange (46-68 km)

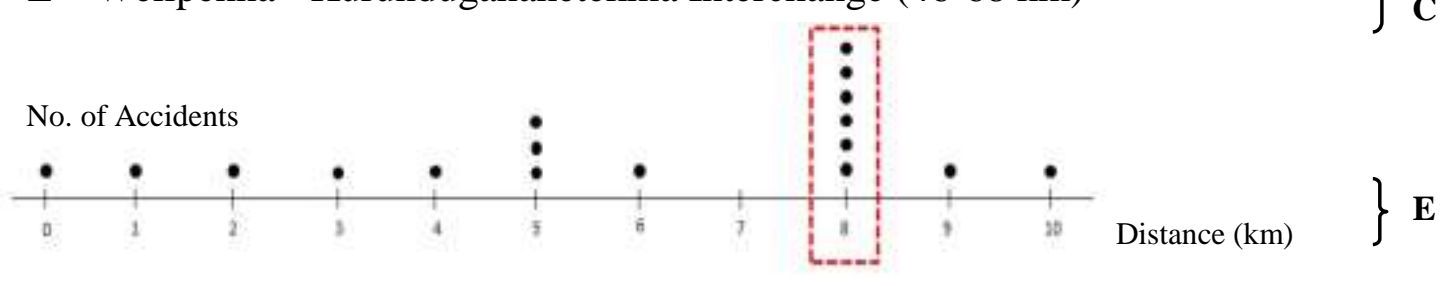

No. of Accidents
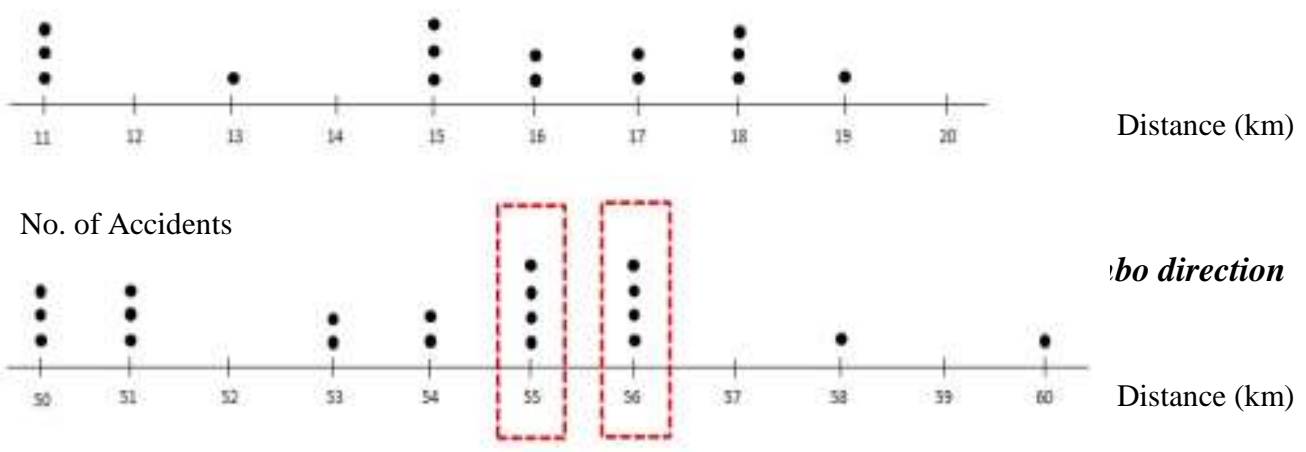

Fig. 18: Dot-Density measure to identify black spots, Matara to Colombo direction Source: Author

In the Matara- Colombo direction, it is identified that the black-spots are located between Welipenna - Kurundugahahetekma Interchanges and Dodangoda to Kottawa interchanges. Then, a dot density measure identifies the specific black-spot which is in between $55 \mathrm{~km}-56 \mathrm{~km}$.

According to the above analysis, particular two points have been identified to analyze the spatial characteristics of Road Landscape.

Point A - 89 km-90 km, Between Baddegama- Pinnaduwa Interchanges -

Colombo - Matara direction

Point B - 55 km- 56 km, Between Welipenna-Kurundugahahetekma Interchanges Matara - Colombo direction

The selected three spatial characteristics have been analyzed using scaled plans, sectional diagrammes, photographic analysis and video recording. This paper indicates only a summarized version of data analysis.

\section{Solidity \& degree of Enclosure}

In this parameter, 'Solidity' and 'Degree of Enclosure' have been analyzed separately. 


\section{Solidity}

The solid \& void spaces and its composition analyzed in Point A and Point B. The experience of driving through solid and void spaces is different. It varies according to the surface material of solid spaces, the distance from the road, the length of the solid/void stretch and the composition of solid/void spaces.

Solidity along the stretch was identified by using scaled spatial plans of Southern Highway.

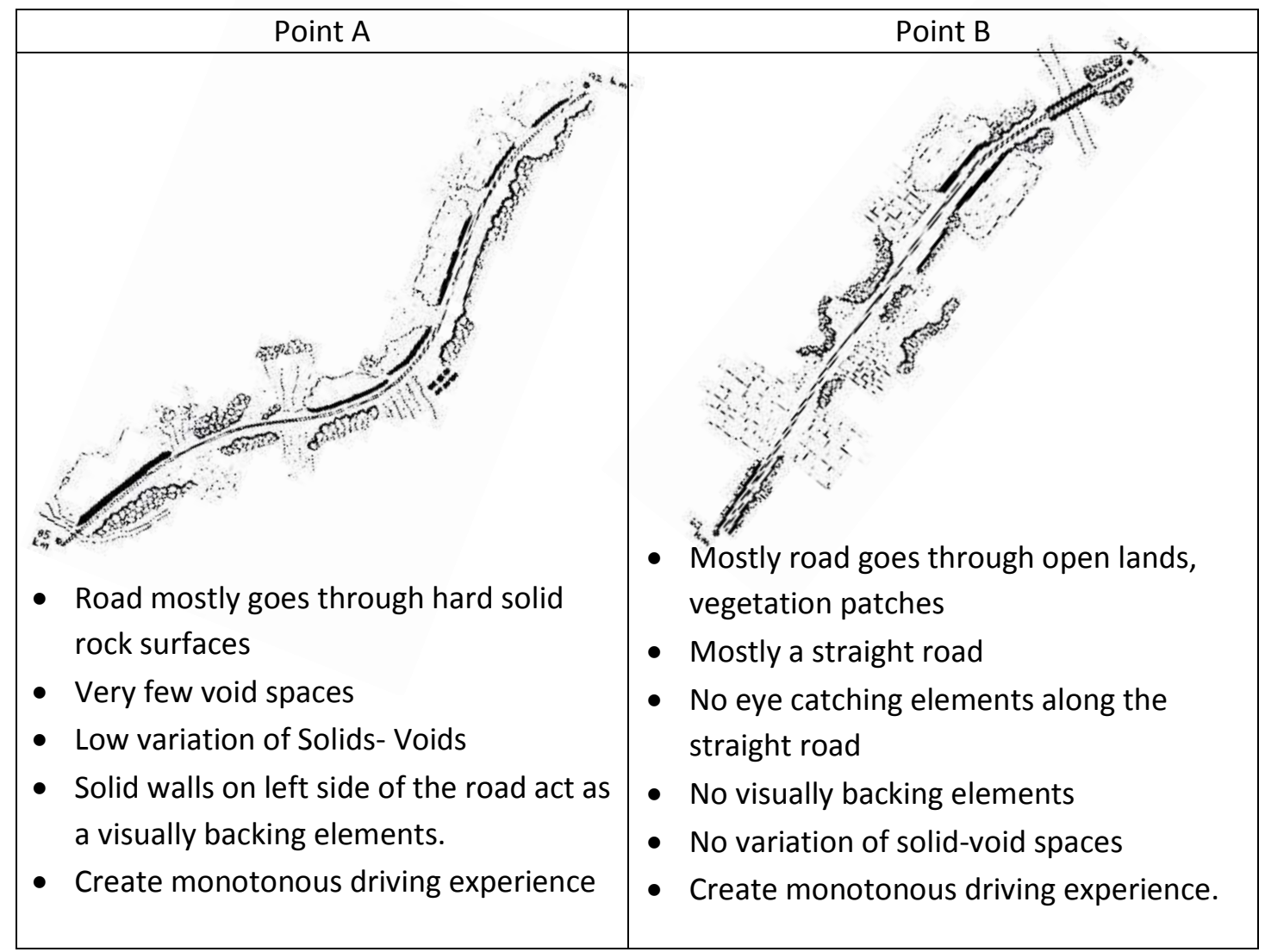

\section{Degree of Enclosure}

The degree of enclosure has been analyzed by using diagrammes of sectional elevations of road section along the identified points.

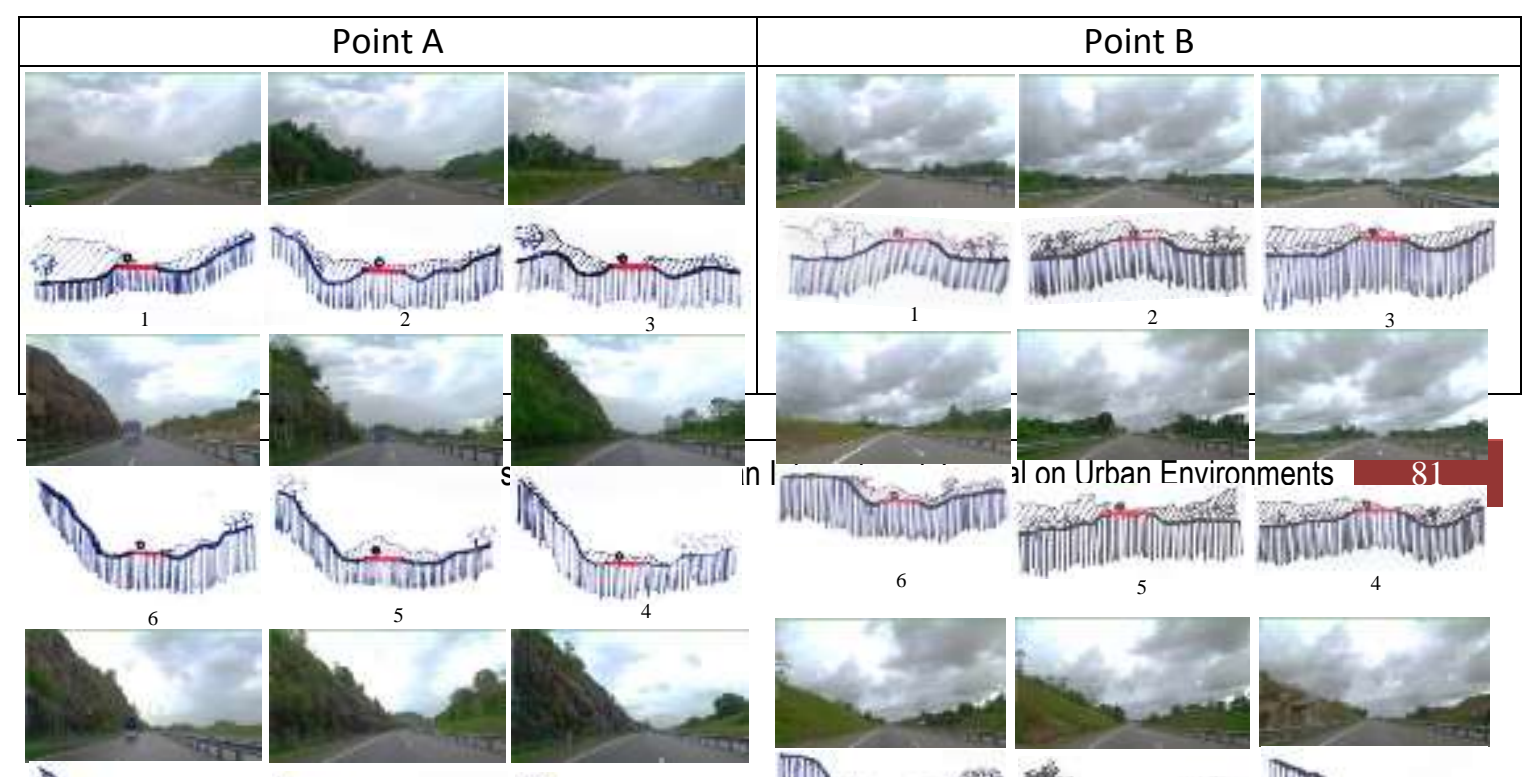


- Mostly enclosed with the left side rocky surface.

- First $3 \mathrm{~km}$ stretch create monotonous environment

- Sudden exposure to open low lands

- Next, $3 \mathrm{~km}$ stretch with enclosed soil slopes

- Low composition of enclosed spaces \& open spaces.

- Create uncomfortable, monotonous driving experience.

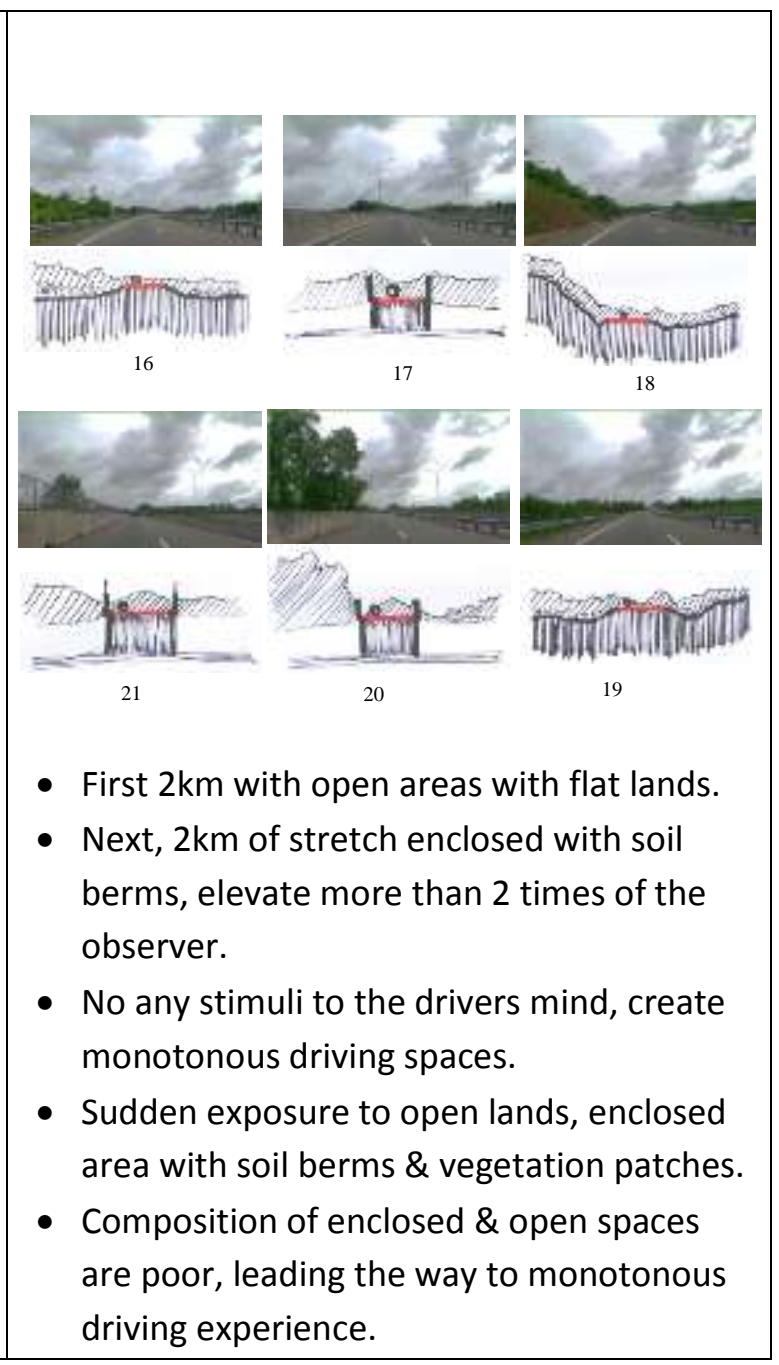

Both having long stretches of enclosed areas or open areas to a highway driving create uncomfortable driving experience to the users. Both situations create monotonous environments which can lead drivers to fatigue, negligence or hypo vigilance. Thus, there should be a better composition of enclosure effect in road landscape of highways.

\section{Differentiate of forms}

People always try to first understand the 'form' of any object. The information processing skills while driving decided the safety of the driving. Always the road landscape impact to the decision making stage of the driving performances. Therefore, the forms of the road landscape is very much important when ensuring the safety on roads.

Drivers always read the front view of the road to identify the form of the landscape. Then realize the detail of the road section. The differentiattion of forms were analyzed with the photographs analysis method, the photographs of the road landscape taken at every 500m intervals. 


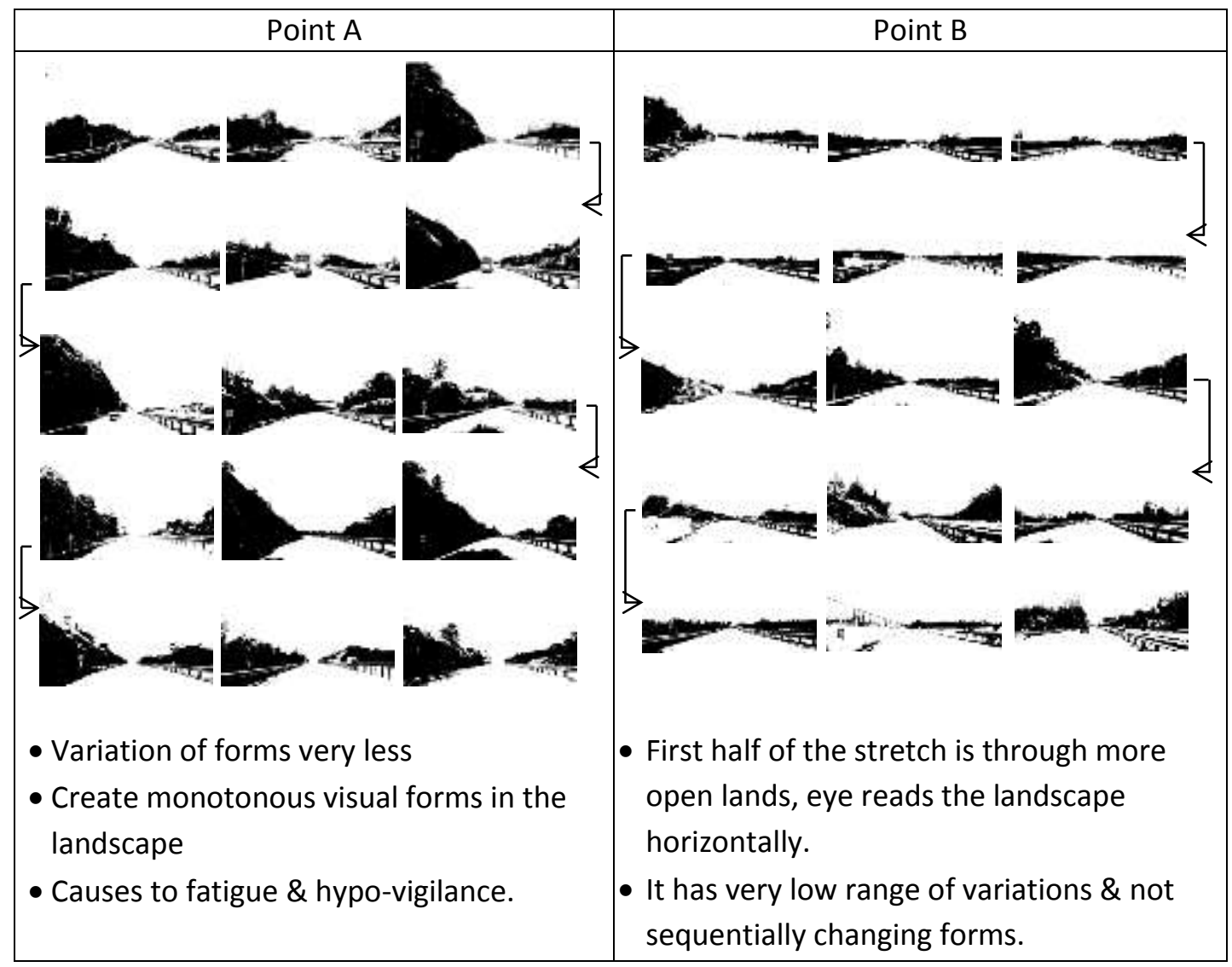

The Point A has mostly vertically variate forms \& Point B has mostly horizontally variate forms. Both points have low variation of forms, leads to driver fatigue with monotonous driving experience.

\section{$>$ Proportion / Scale of the space with respect to the observer}

Proportion of the space with respect to the observer/ driver is one of the most important characteristics in road landscapes which directly affect driving behaviour. This characteristic has been analyzed by using scale diagrammes of road sections in both points. 


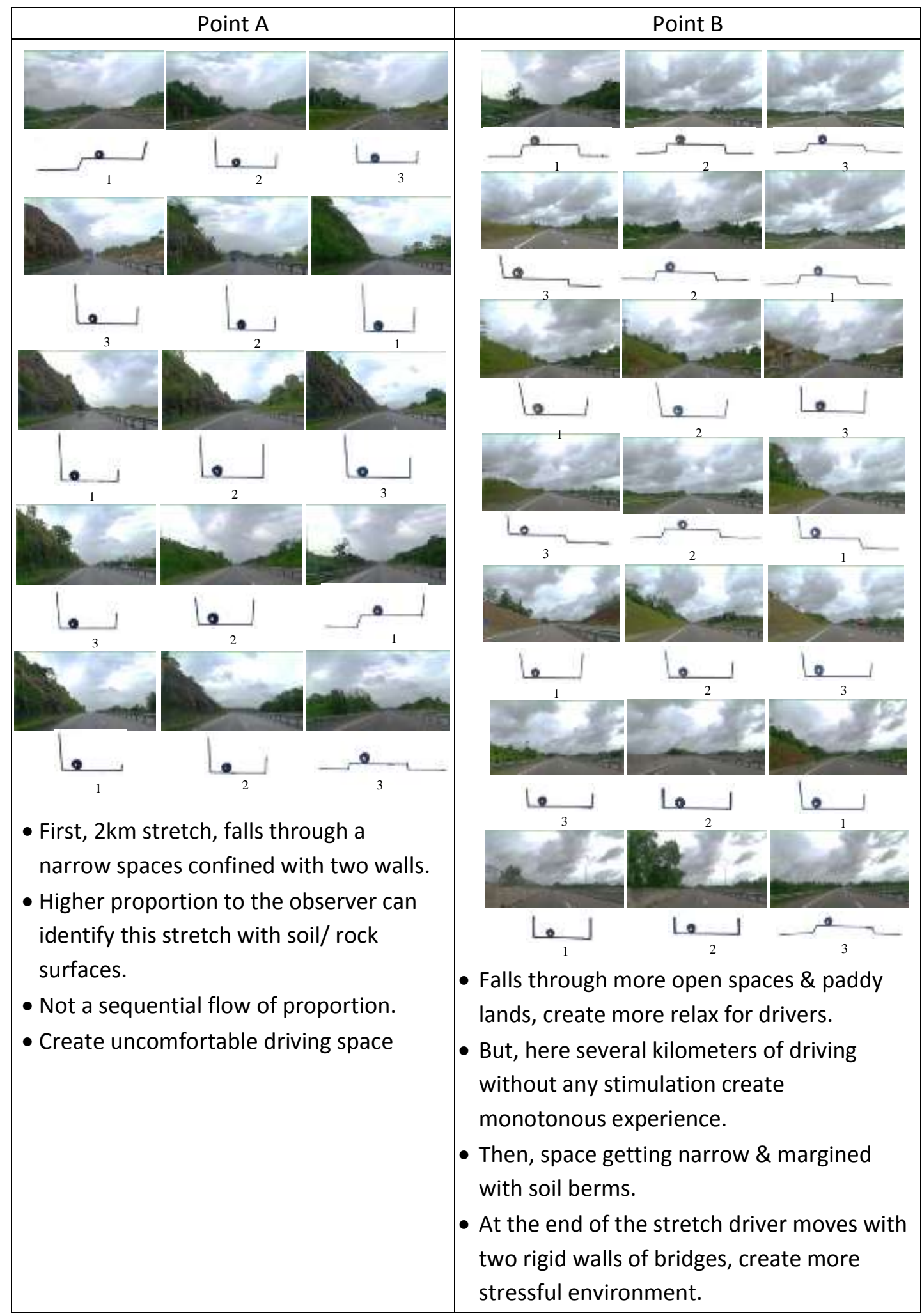


Driving is a sequential experience to the driver. It should have correct combination of proportion of the space to the driver, otherwise it creates more stressful environment to the driving behaviour. Point A has higher proportioned spaces than Point B. Side walls with higher proportions create an uncomfortable driving environment which reduces driving performances. Point B has very low proportion (mostly flat areas) and sudden rigid walls. Both situations create stressful driving environments causing poor driving performances.

\section{Conclusion}

Through the literature review, three major spatial characteristics, 'solidity and degree of enclosure', 'differentiate of forms' and 'proportion/scale of the space with respect to the observer' were identified to analyze the roadside landscape in Southern Expressway.

The two 'black-spots', accident-prone areas, were identified to assess the spatial characteristics in road landscape. The 'solidity and degree of enclosure' is analyzed by variations through solid and void spaces and variation of enclosure effect. The variation of solid and void spaces are minimum in two identified spaces, which creates a monotonous visual environment. It pulled drivers into a very lethargic form of driving, eventually, it causes driver fatigue and hypo-vigilance. The degree of enclosure effect is different in two black-spot areas, one with a high profile of enclosure effect and another area has a low profile of enclosure. But, in both situations, the drivers move through a monotonous road environment, causing driver fatigue and drowsy driving. The roadside landscape form variation have been analyzed by the second characteristic, 'differentiate of forms'. It is found that monotonous landscape formations are continued in both areas, and reduces driving performances. The 'proportion/scale of the space' is another identified spatial character along the highway, which makes troublesome for the drivers. In one area, drivers move mostly through very confined spaces, and in other areas, the space is more open. Both situations make influences on driver's psychological imbalance; finally causing to reduce driving performances.

Generally, the road safety research is conducted as simulator studies in laboratories, because of its' difficulty to replicate and control the real-world situations. However, this study employed a qualitative analysis of spatial factors. The study also concentrated on analyzing the selected important spatial characteristics of the roadside landscape. However, there are many other spatial characteristics in road landscapes to be analyzed. They are recommended for future studies. In addition, there is a need to develop an equitable method of analyzing the human perception of live experience, which cannot be replicated.

The study emphasizes an evaded part of most of the major road construction projects in Sri Lanka, 'the evaluation of roadside landscape'. As per the study, driving is an activity of experiencing landscape when people are in motion. The drivers need to be attached to their driving space to gain information for ensuring the safety. Thus the spatial characteristics of road landscapes contribute to shape-up the driving space. Therefore, when planning and constructing the roads, it should consider not only the engineering aspects of road construction, but also, the spatial characteristics of road landscapes. The 
study highlighted the spatial characteristics in roadside landscapes and their impacts on driving behaviour.

\section{References}

Antonson , H., Mårdh, S., Wiklund, M., \& Blomqvist, G. (2009). The Surrounding Landscape Effect on Driving Behaviour: A Driving Simulator Study. Journal of Environmental Psychology, 493-502.

Appleyard, D., Lynch, K., \& Myer, J. R. (1965). The view from the road. Cambridge: The MIT Press.

Gong, D., Xie, H., XU, X., FU, X., \& LI, H. (2005). A new concept of landscape design in highway construction.

Lal, S. K., \& Craig, A. (2001, Nov. 14). A critical review of the psychop2hysiology of driver fatigue. Biological Psychology, 55, 173-194.

Matijosaitiene, I. (2011). The Principles Of Formation Of The Hedonomic Road Landscape. Kaunas: Doctoral Dissertation, Kaunas University of Technology.

Matijošaitienè, I., \& Navickaite, K. (2012). Aesthetics and Safety of Road Landscape: are they Related? Sustainable Architecture and Civil Engineering, 20-25.

Mok, J. H., Landphair, H. C., \& Naderi, J. R. (2006). Landscape improvement impacts on roadside safety in Texas. Landscape and Urban Planning, 263-274.

Schutt, J. R., Phillips, K. L., \& Landphair, H. C. (2001). Guidelines for Aesthetic Design in Highway Corridors: Tools and Treatments for Texas Highways. Texas: Texas Department of Transportation.

Sivak, M. (1980). Human factors and highway-accident causation: some theoretical considerations. Highway Safety Research Institute, University of Michigan, 6164.

Somasundaraswaran, A. K. (2006). Accident Statistics in Sri Lanka. IATSS Research, Vol.30(No.01).

Thiffault, P., \& Bergeron, J. (2002). Monotony of road environment and driver fatigue: a simulator study. Accident Analysis and Prevention, 381-391.

Weekly Epidemiological Report, Ministry of Health. (2013, January 12th - 18th). Vol. 40(No.03).

Yiling, C., \& Ying, J. (2015). Difference Between the Urban Road Landscape Design and the Highway Landscape Design (Vol. 5). 